\title{
Qualidade da água no consórcio de peixes com arroz irrigado
}

\author{
Water quality in combination of the fish culture and irrigate rice \\ Jaqueline Ineu Golombieski ${ }^{1}$ Enio Marchezan ${ }^{2}$ Mozart Borges Monti ${ }^{3}$ \\ Lindolfo Storck ${ }^{2}$ Edinalvo Rabaioli Camargo ${ }^{4}$ \\ Fernando Machado dos Santos ${ }^{4}$
}

\section{RESUMO}

\begin{abstract}
O objetivo deste trabalho foi avaliar a qualidade da água utilizada no consórcio de peixes com arroz irrigado. O experimento foi conduzido em área de várzea, com sistema pré-germinado de cultivo de arroz associado ao cultivo de carpas e jundiá, onde semanalmente foram monitorados os níveis de oxigênio dissolvido, temperatura, $p H$, dureza, alcalinidade total, amônia, nitrito e transparência da água. As características físico-químicas da água (temperatura, $\mathrm{pH}$, dureza, alcalinidade,amônia e nitrito) não afetam o crescimento e o desenvolvimento dos peixes no consórcio com arroz irrigado para as espécies cultivadas (60\% de carpa húngara, 20\% de carpa capim, 10\% de jundiá, 5\% de carpa prateada e 5\% de carpa cabeça grande). Embora as densidades de peixes utilizadas e as épocas de colocação dos alevinos afetem certos parâmetros de qualidade da água (oxigênio dissolvido e transparência da água) em alguns períodos, em geral eles se mantêm em níveis adequados de acordo com os padrões para as espécies.
\end{abstract}

Palavras-chave: oxigênio dissolvido, temperatura, $p H$, dureza, alcalinidade total, transparência da água.

\section{ABSTRACT}

The goal of the present work was to evaluate quality parameters of the water utilized in combination of the fish culture with irrigate rice. The experiment was carried in low land area, with rice pre-germinate system associated with farming of carps and silver catfish, where the levels of dissolved oxygen, temperature, $\mathrm{pH}$, hardness, total alkalinity, ammonia, nitrite and water transparency were weekly monitored. The physical-chemical characteristics of the water (temperature,
pH, hardness, total alkalinity, ammonia, and nitrite) do not affect the growth and development of the fish in combination with irrigate rice for cultived species (60\% commom carp, $20 \%$ grass carp, $10 \%$ silver catfish, $5 \%$ silver carp and $5 \%$ bighead carp) Although, the quantities of fish utilized and time of entry fingerlings affect certain water quality parameters (dissolved oxygen and water transparency) in general they maintain in levels adequate to with the standard for these species.

Key words: dissolved oxygen, temperature, $p H$, hardness, total alkalinity, water transparency.

\section{INTRODUÇÃO}

A avaliação dos níveis de qualidade da água para peixes, incluindo oxigênio dissolvido, temperatura, $\mathrm{pH}$, amônia, nitrito, dureza e alcalinidade total, e transparência são importantes para se prever como estão as condições ambientais para a vida destes. Neste sentido, a qualidade da água na criação dos peixes consorciados com o arroz irrigado é um aspecto fundamental para garantir seu bom desenvolvimento e sobrevivência (MOHANTY et al., 2004).

A rizipiscicultura é um sistema de produção caracterizado pelo cultivo consorciado de arroz irrigado e a criação de peixes. Essa prática reduz o uso de máquinas, conserva o ambiente e proporciona aumento de renda por área, pois o peixe prepara o solo para o próximo cultivo do arroz irrigado, recicla a

\footnotetext{
${ }^{1}$ Programa de Pós-graduação (PPG) em Agronomia, Universidade Federal de Santa Maria (UFSM), 97105-900, Santa Maria, RS, Brasil. E-mail: golombieski@smail.ufsm.br. Autor para correspondência.

${ }^{2}$ Departamento de Fitotecnia, UFSM, Santa Maria, RS, Brasil.

${ }^{3}$ Engenheiro Agrônomo, Autônomo, Brasil.

${ }^{4}$ Programa de Pós-graduação em Agronomia, UFSM, Santa Maria, RS, Brasil.
} 
matéria orgânica e consome sementes de plantas invasoras no solo, contribuindo também para a redução de larvas de insetos e caramujos (SATO, 2002).

O oxigênio dissolvido em tanques é monitorado por ser o primeiro parâmetro de qualidade da água que pode ser afetado através do aumento da alimentação e do metabolismo dos peixes. Muitos casos da depleção de oxigênio dissolvido em tanques com peixes são resultado de altas taxas de respiração noturna pela densa comunidade planctônica, respiração dos peixes, respiração de organismos bentônicos e decomposição bacteriana (SUMAGAYSAY-CHAVOSO \& SAN DIEGOMcGLONE, 2003). As principais fontes de oxigênio para a água são a atmosfera e a fotossíntese (ESTEVES, 1988). A temperatura da água influencia fortemente no consumo de oxigênio e também na capacidade de carregar oxigênio na água (GOLOMBIESKI et al., 2003), pois a solubilidade do oxigênio depende do fator temperatura associado a pressão, sendo que com a elevação da temperatura e diminuição da pressão, ocorre redução da solubilidade do oxigênio (ESTEVES, 1988). O pH da água é um importante fator para assegurar uma boa produção de peixes. A faixa de $\mathrm{pH}$ de 6,5 a 9,0 é usualmente sugerida para a criação de peixes, mas a faixa ótima pode diferir para diferentes espécies. Baixos níveis de $\mathrm{pH}$ reduzem o crescimento e a reprodução dos peixes (LOPES et al., 2001).

A amônia é o maior resíduo nitrogenado produzido através do catabolismo dos aminoácidos, sendo, na água, reduzida a nitrito pela nitrificação bacteriana antes de ser convertida a nitrato (COSTA et al., 2004). Ela é tóxica não apenas para peixes, mas também para animais aquáticos, especialmente em tanques com baixas concentrações de oxigênio dissolvido, e existe em ambas as formas: ionizada $\left(\mathrm{NH}_{4}^{+}\right)$e não-ionizada $\left(\mathrm{NH}_{3}\right)$, sendo sua toxicidade atribuída principalmente à última forma (FOSS et al., 2003). Níveis tóxicos de amônia não-ionizada para curtas exposições usualmente são reportados e ficam entre 0,6 e $2 \mathrm{mg} \mathrm{L}^{-1}$. Dois principais fatores afetam a concentração de amônia em tanques: a taxa de excreção pelos peixes e a difusão pelos sedimentos que representa uma parte da amônia externa. Algas utilizam amônia para o crescimento e produção de oxigênio, e a presença de maiores cargas nitrogenadas em tanques aumenta a produtividade primária dos tanques, com mais alimentos disponíveis para peixes para seu máximo crescimento (EL-SHAFAI et al., 2004).

O nitrito é um produto intermediário da transformação da amônia em nitrato, e pode ser tóxico para peixes (FRANCES et al., 1998). Como resultado da ação da nitrificação bacteriana, a amônia é reduzida a nitrito, e em sistemas fechados, bem como tanques de terra, ambos podem acumular para níveis tóxicos. $\mathrm{O}$ aumento nas concentrações de nitrito na água induz a acumulação deste no sangue e tecidos, e via reações complexas produzindo derivados tóxicos com ação deletéria em processos fisiológicos dos peixes (COSTA et al., 2004).

A dureza total é a concentração de todos os cátions divalentes na água, sendo o cálcio $\left(\mathrm{Ca}^{2+}\right)$ e o magnésio $\left(\mathrm{Mg}^{2+}\right)$ os cátions mais comuns em quase todos os sistemas de água doce. O valor recomendado de dureza total para a cultura de peixes em tanques é acima de 20mg L $\mathrm{L}^{-1} \mathrm{CaCO}_{3}$ (BOYD \& EGNA, 1997). Este parâmetro influencia no crescimento do fitoplâncton na água e além disto, o $\mathrm{Ca}^{2+}$ é essencial para vários processos biológicos dos peixes como construção óssea e coagulação sanguínea, entre outras funções celulares, sendo sua ingestão regulada pela alimentação ou pela absorção branquial (FLIK \& VERBOST, 1995). Quanto à alcalinidade total da água, segundo ESTEVES (1988), ela representa a capacidade que um sistema aquoso tem de neutralizar ácidos, e esta capacidade depende de alguns compostos, principalmente carbonatos, bicarbonatos e hidróxidos. A alcalinidade aumenta o pH e por conseqüência a amônia torna-se mais tóxica com o aumento da alcalinidade. Dureza e alcalinidade são relativamente estáveis, mas podem mudar com o tempo, geralmente semanas ou meses, dependendo do $\mathrm{pH}$ e do conteúdo mineral da água e do solo(WURTS \& DURBOROW, 1992).

Os peixes utilizados no estado do RS na rizipiscicultura, são as espécies de carpas, que em sistema de policultivo proporcionam um melhor aproveitamento do ambiente em função do hábito alimentar diferenciado. A carpa húngara (Cyprinus carpio) (omnívora) é a espécie que ingere sementes, minhocas, insetos, pequenos moluscos, entre outros, e que remove o solo à procura de alimentos, executando assim o seu preparo; a carpa capim (Ctenopharyngodon idella), é a espécie de hábito alimentar herbívoro; as carpa cabeça grande (Aristichthys nobilis) e carpa prateada (Hypophthalmicthys molitrix), são espécies filtradoras, alimentando-se de fitoplâncton e zooplâncton, respectivamente (COTRIM et al., 2001). Já o jundiá (Rhamdia quelen), espécie de hábito alimentar também omnívoro, foi utilizado no experimento por ser uma espécie nativa amplamente distribuída no sul do Brasil e bem aceita pelo mercado consumidor (GOMES et al., 2000). Assim, o objetivo do presente experimento foi de avaliar alguns parâmetros de qualidade da água em área de rizipiscicultura. 


\section{MATERIAL E MÉTODOS}

O experimento foi conduzido nos anos agrícolas de 2001/2002 e 2002/03, em solo classificado como Planossolo Hidromórfico Eutrófico arênico (Unidade de Mapeamento Vacacaí) (EMBRAPA, 1999), com as seguintes características químicas no início do experimento: argila $=25 \% ; \mathrm{pH}\left(\mathrm{H}_{2} \mathrm{O}\right)=5,0 ; \mathrm{pH}($ solo $)=5,5$; $\mathrm{P}$ (fósforo) $=8,1 \mathrm{mg} \mathrm{L}^{-1} ; \mathrm{K}$ (potássio) $=47,6 \mathrm{mg} \mathrm{L}^{-1} \mathrm{e}$ M.O. (matéria orgânica) $=2,1 \% \mathrm{~m} / \mathrm{v}$, conforme análise de solo realizada.

O delineamento experimental foi de blocos ao acaso, em esquema trifatorial (Ano x Densidade $\mathrm{x}$ Época), com três repetições. Os tratamentos utilizados foram duas densidades de povoamento dos peixes: D1 $=6000$ alevinos ha ${ }^{-1}$ e D2 $=3000$ alevinos ha ${ }^{-1}$ e três épocas de colocação: E1= na semeadura; E2= 20 dias após a semeadura e E3 = após a colheita do arroz. Após o sorteio do experimento, em cada época de colocação dos alevinos foram aplicadas as duas densidades de povoamento. As proporções de peixes utilizadas foram: 60\% de carpa húngara (Cyprinus carpio), 20\% de carpa capim (Ctenopharyngodon idella), $5 \%$ de carpa cabeça grande (Aristichthys nobilis), 5\% de carpa prateada (Hypophthalmicthys molitrix) e $10 \%$ de jundiá (Rhamdia quelen).

O sistema de cultivo utilizado foi o prégerminado e a cultivar foi IRGA 419, na densidade de $120 \mathrm{~kg} \mathrm{ha}^{-1}$. As parcelas experimentais constituíam-se de $480 \mathrm{~m}^{2}(40 \mathrm{~m} \times 12 \mathrm{~m})$ com uma área de refúgio de 5,8\% da área total da parcela, com 0,50m de largura e $0,70 \mathrm{~m}$ de profundidade. Os alevinos apresentavam comprimento aproximado entre 5 a $10 \mathrm{~cm}$, quando foram colocados nas duas primeiras épocas de entrada. Durante todo o período de desenvolvimento da cultura do arroz, manteve-se a lâmina de água contínua, com profundidade aproximada de $0,15 \mathrm{~m}$.

No primeiro ano agrícola (2001/02), após a colheita do arroz (abril de 2002), a área experimental foi mantida por um período de 15 dias com água somente no refúgio e, em seguida, elevada gradativamente a lâmina de água das parcelas, suficiente para a cobertura da resteva do arroz. Os tratamentos referentes à primeira e segunda épocas de colocação (E1 e E2) permaneceram com peixes durante todo o ciclo da cultura do arroz irrigado; já no tratamento referente à terceira época de povoamento (E3), os alevinos foram colocados na lavoura 15 dias após a colheita do arroz. Após isto, os peixes permaneceram na área até outubro de 2002, quando foi realizada a despesca. No segundo ano, após a colheita do arroz (março de 2003), efetuouse a entrada dos alevinos referentes à terceira época de povoamento (E3), com tamanho de 15 a $20 \mathrm{~cm}$ nesta ocasião. Os peixes permaneceram nas unidades experimentais até a despesca que foi realizada em outubro de 2003.

Durante o período experimental, foram monitorados semanalmente os parâmetros físicoquímicos da água: temperatura e oxigênio dissolvido (Oxímetro Oaktron), pH (pHmetro Schott Handylab 1), nitrito, alcalinidade total e amônia total (Kits Alfa Tecnoquímica, SC, Brasil); dureza total (GREENBERG et al., 1976), e transparência da água (Disco de Secchi). A amônia não-ionizada foi determinada segundo PIPER et al. (1982). A água analisada foi coletada na área do refúgio (manhã - 8h ou tarde - 14h), em frascos de cor âmbar, tomando-se uma amostra por repetição (parcela), sendo esta encaminhada ao laboratório para posterior realização de técnicas. As avaliações referentes ao oxigênio dissolvido (a $15 \mathrm{~cm}$ de profundidade) e transparência da água, foram realizadas diretamente nas parcelas experimentais. Após a despesca dos peixes da área aplicou-se cal virgem (óxido de cálcio) somente na área do refúgio para desinfecção, na proporção de $700 \mathrm{~kg} \mathrm{ha}^{-1}$. O nivelamento da superfície do solo nas parcelas experimentais foi corrigido manualmente, e após aplicou-se calcário dolomítico na proporção de $1000 \mathrm{~kg}$ ha $^{-1}$, a fim de manter níveis adequados de dureza e alcalinidade total da água.

Os dados de oxigênio dissolvido, temperatura, $\mathrm{pH}$, transparência, dureza e alcalinidade total foram submetidos à análise da variância e as médias comparadas pelo teste de Duncan em nível de $5 \%$ de probabilidade de erro $(\mathrm{p}<0,05)$.

\section{RESULTADOS E DISCUSSÃO}

Na tabela 1, encontram-se os dados de oxigênio dissolvido, temperatura, transparência, $\mathrm{pH}$, dureza e alcalinidade da água. Houve diferença significativa nos níveis de oxigênio dissolvido e temperatura entre os anos e épocas de colocação dos peixes, sendo que a E3 apresentou níveis mais baixos de oxigênio e temperatura em relação às outras duas épocas. Porém, a concentração de oxigênio dissolvido na parcela testemunha apresentou-se mais elevada devido ao menor consumo deste gás, já que não havia a presença de peixes nesta área. A transparência da água não foi afetada significativamente pelos fatores densidades e épocas de colocação dos peixes. Os valores médios de $\mathrm{pH}$ ficaram situados entre as médias de 6,0 a 7,6. Houve diferença significativa nos níveis de dureza total entre os anos agrícolas experimentais. Já os níveis de alcalinidade total, mostraram diferenças significativas 
Tabela 1 - Médias dos valores físico-químicos da água em resposta aos anos, densidades de povoamento e épocas de colocação dos alevinos. Santa Maria, RS, 2004.

\begin{tabular}{|c|c|c|c|c|c|c|}
\hline Ano & $\begin{array}{l}\text { Oxigênio } \\
\left(\mathrm{mg} \mathrm{L}^{-1}\right)\end{array}$ & $\begin{array}{c}\text { Temperatura } \\
\left({ }^{\circ} \mathrm{C}\right)\end{array}$ & $\begin{array}{c}\text { Transparência } \\
\text { (cm) }\end{array}$ & $\begin{array}{c}\mathrm{pH} \\
\text { (unidades) }\end{array}$ & $\begin{array}{c}\text { Dureza } \\
\left(\mathrm{mg} \mathrm{L}^{-1} \mathrm{CaCO}_{3}\right)\end{array}$ & $\begin{array}{c}\text { Alcalinidade } \\
\left(\mathrm{mg} \mathrm{L}^{-1} \mathrm{CaCO}_{3}\right)\end{array}$ \\
\hline $2001 / 02$ & $5,7^{\mathrm{a}}$ & $21,1^{a}$ & $19,5^{\text {ns }}$ & $6,3^{a}$ & $20,7^{a}$ & $19,5^{\text {a }}$ \\
\hline $2002 / 03$ & $3,9^{b}$ & $21,5^{b}$ & 16,7 & $6,5^{b}$ & $42,8^{b}$ & $19,0^{b}$ \\
\hline \multicolumn{7}{|l|}{ Densidade } \\
\hline D1 (6000 al) & $4,8^{\mathrm{ns}}$ & $21,3^{\text {ns }}$ & $16,8^{\mathrm{ns}}$ & $6,3^{\mathrm{a}}$ & $30,2^{\text {ns }}$ & $15,3^{\text {ns }}$ \\
\hline D2 (3000 al) & 5,0 & 21,2 & 19,4 & $6,4^{\mathrm{b}}$ & 29,4 & 15,6 \\
\hline \multicolumn{7}{|l|}{ Época } \\
\hline E1 (semeadura) & $5,1^{\mathrm{a}}$ & $22,5^{a}$ & $16,1^{\mathrm{ns}}$ & $6,5^{\mathrm{a}}$ & $31,0^{\mathrm{a}}$ & $16,7^{\mathrm{a}}$ \\
\hline E2 (20 DAS) & $5,0^{a}$ & $21,3^{b}$ & 19,5 & $6,3^{b}$ & $30,3^{a}$ & $15,2^{b}$ \\
\hline E3 (após colh.) & $4,6^{\mathrm{b}}$ & $19,0^{c}$ & 19,3 & $6,3^{b}$ & $27,1^{\mathrm{b}}$ & $13,6^{c}$ \\
\hline Testemunha $^{1}$ & 5,8 & 21,2 & 33,7 & 6,4 & 26,7 & 17,8 \\
\hline Média & 4,9 & 21,3 & 18,1 & 6,3 & 29,8 & 15,4 \\
\hline CV (\%) & 30,8 & 10,4 & 49,2 & 4,5 & 43,9 & 40,8 \\
\hline
\end{tabular}

${ }^{\text {ns }}$ Teste F não significativo, na coluna.

* Médias seguidas por letras diferentes, na coluna, diferem entre si pelo teste de Duncan em nível de 5\% de probabilidade de erro (DAS = Dias após a semeadura).

${ }^{1}$ Parcela testemunha (sem peixes)- média de dois anos experimentais.

entre as épocas de colocação dos alevinos, com a E3 apresentando níveis mais baixos.

Na tabela 2, estão apresentados os dados mensais de qualidade da água. Os níveis de oxigênio dissolvido e temperatura sofreram variações significativas ao longo dos meses. A transparência da água manteve-se na faixa média mensal de 11,6 a 22,9cm ao longo do período, a alcalinidade total entre 10,6 e $37 \mathrm{mg} \mathrm{L}^{-1} \mathrm{CaCO}_{3}$ e a dureza total de 10,8 a $63,2 \mathrm{mg} \mathrm{L}^{-1}$ $\mathrm{CaCO}_{3}$.

Os níveis de amônia total mantiveram-se na faixa de 0,1 a $4,0 \mathrm{mg} \mathrm{L}^{-1}$ com amônia não-ionizada entre 0,0034 e $0,0098 \mathrm{mg} \mathrm{L}^{-1}$. Já os valores de nitrito apresentaram poucas variações durante o período experimental, estando numa faixa de 0,025 a $0,1 \mathrm{mg}$ $\mathrm{L}^{-1}$.

Sabe-se que a concentração de oxigênio dissolvido é um dos fatores de qualidade da água que mais afeta as espécies cultivadas. Quando os níveis de oxigênio dissolvido nos tanques de aqüicultura se tornam baixos, os organismos cultivados podem ficar estressados ou mesmo morrerem. O fitoplâncton existente na água produz o oxigênio necessário à respiração. A quantidade de oxigênio requerida pelos organismos aquáticos é variável e depende de fatores como espécie, tamanho, quantidade de alimento ingerido e temperatura da água (BOYD \& EGNA, 1997). Outro fato importante é que a transparência da água interfere no teor de oxigênio desta. Quando um corpo d'água apresenta maior transparência, a radiação solar pode atingir maiores profundidades, proporcionando maior produção de oxigênio pelos organismos fotossintetizantes.

A temperatura da água variou em média de 15,1 a $28,4^{\circ} \mathrm{C}$, estando as alterações relacionadas às estações sazonais, reguladas pela incidência de luz solar neste período. Esta ampla faixa de variação, característica da região sul do país, que apresenta estações bem definidas, não afetou a sobrevivência das espécies cultivadas neste experimento. Para ROTHUIS et al. (1998), o desenvolvimento do arroz e o baixo nível da água tem um impacto no ambiente aquático, assim como no peixe. Freqüentemente a fertilização realizada cedo no ciclo da cultura do arroz e a baixa densidade de plantas neste estágio, estimula o desenvolvimento de fitoplâncton, principal responsável pelos altos níveis de oxigênio na água. Porém, mudanças progressivas através do crescimento das plantas de arroz, e uma limitada disponibilidade de nutrientes, diminuem o desenvolvimento de plâncton.

A faixa ideal de transparência da água para o cultivo de peixes é de 30 a 40cm (CASTAGNOLLI, 1992). Neste experimento as médias de transparência da água permaneceram um pouco abaixo desses valores devido principalmente à carpa húngara, que remove detritos do fundo do tanque, deixando esta água mais turva. Nos meses com temperaturas mais baixas, contudo, a transparência da água foi maior, devido a menor taxa metabólica dos peixes. MOHANTY et al. (2004) em experimentos conduzidos com rizipiscicultura na Índia, encontraram valores de 
Tabela 2 - Médias mensais dos valores físico-químicos da água com peixes em várzea, obtidos em dois anos (2001/02 e 2002/03). Santa Maria, RS, 2004.

\begin{tabular}{|c|c|c|c|c|c|c|}
\hline Meses & $\begin{array}{l}\text { Oxigênio } \\
\left(\mathrm{mg} \mathrm{L}^{-1}\right)\end{array}$ & $\begin{array}{c}\text { Temperatura } \\
\left({ }^{\circ} \mathrm{C}\right)\end{array}$ & $\begin{array}{c}\text { Transparência } \\
\text { (cm) }\end{array}$ & $\begin{array}{c}\mathrm{pH} \\
\text { (unidades) }\end{array}$ & $\begin{array}{c}\text { Dureza } \\
\left(\mathrm{mg} \mathrm{L}^{-1} \mathrm{CaCO}_{3}\right)\end{array}$ & $\begin{array}{c}\text { Alcalinidade } \\
\left(\mathrm{mg} \mathrm{L}^{-1} \mathrm{CaCO}_{3}\right)\end{array}$ \\
\hline Novembro & $7,0^{b}$ & $23,8^{d}$ & $11,6^{\mathrm{f}}$ & $7,2^{b}$ & $40,7^{b}$ & $37,0^{a}$ \\
\hline Dezembro & $7,8^{a}$ & $27,8^{a}$ & $17,7^{\text {bcde }}$ & $7,6^{\mathrm{a}}$ & $34,5^{\text {bc }}$ & $25,1^{\mathrm{b}}$ \\
\hline Janeiro & $5,4^{\mathrm{d}}$ & $28,4^{a}$ & $18,4^{\text {abcd }}$ & $6,5^{c}$ & $63,2^{a}$ & $26,5^{b}$ \\
\hline Fevereiro & $3,2^{f}$ & $25,4^{\text {bc }}$ & $14,5^{\text {cdef }}$ & $6,2^{f}$ & - & $11,3^{\text {de }}$ \\
\hline Março & $1,8^{g}$ & $25,9^{b}$ & $13,3^{\text {ef }}$ & $6,2^{f}$ & $21,3^{e}$ & $10,6^{\mathrm{e}}$ \\
\hline Abril & $2,8^{f}$ & $24,9^{\mathrm{c}}$ & $22,2^{a b}$ & $6,2^{\text {ef }}$ & $32,5^{\text {cd }}$ & $14,4^{d}$ \\
\hline Maio & $3,0^{f}$ & $19,5^{\mathrm{g}}$ & $22,9^{a}$ & $6,4^{\text {cd }}$ & $58,9^{\text {a }}$ & $19,3^{\mathrm{c}}$ \\
\hline Junho & $4,7^{\mathrm{e}}$ & $15,9^{\mathrm{i}}$ & $20,5^{a b}$ & $6,2^{\text {ef }}$ & $26,3^{\text {de }}$ & $13,3^{\text {de }}$ \\
\hline Julho & $5,6^{d}$ & $17,2^{\mathrm{h}}$ & $20,8^{a b}$ & $6,3^{\text {de }}$ & $23,8^{e}$ & $14,4^{\mathrm{d}}$ \\
\hline Agosto & $6,1^{c}$ & $15,1^{\mathrm{j}}$ & $19,3^{a b c}$ & $6,3^{\text {ef }}$ & $22,7^{\mathrm{e}}$ & $13,2^{\text {de }}$ \\
\hline Setembro & $5,4^{d}$ & $20,9^{f}$ & $13,7^{\text {def }}$ & $6,3^{\text {ef }}$ & $14,0^{\mathrm{f}}$ & 12,9 de \\
\hline Outubro & $5,4^{d}$ & $22,1^{\mathrm{e}}$ & $12,9^{f}$ & $6,0^{\mathrm{g}}$ & $10,8^{f}$ & $10,6^{\mathrm{e}}$ \\
\hline
\end{tabular}

* Médias seguidas por letras diferentes, na coluna, diferem pelo teste de Duncan em nível de 5\% de probabilidade de erro.

transparência da água entre 16 e 57cm, utilizando policultivo de larvas de carpas (Catla catla, Labeo rohita, Cirrhinus mrigala e Cyprinus carpio) e camarão de água doce (Macrobrachium rosenbergii).

Geralmente existe uma flutuação diária de uma ou duas unidades de $\mathrm{pH}$ em tanques de cultivo de água doce, que se deve a mudanças na taxa de fotossíntese do fitoplâncton e outras plantas aquáticas em função da luminosidade e fotoperíodo, mas normalmente ele encontra-se na faixa de 6,0-8,0 nos tanques (BALDISSEROTTO, 2002). Existe uma estreita relação entre $\mathrm{pH}$ e níveis de gás carbônico na água, já que peixes consomem oxigênio e liberam gás carbônico, fazendo com que o $\mathrm{pH}$ da água diminua. MOHANTY et al. (2004), estudando pH em rizipiscicultura, encontraram variações entre 6,0 e 8,8. Neste experimento, o pH manteve-se em um nível aceitável para as espécies cultivadas.

A dureza total variou significativamente entre os anos agrícolas experimentais, provavelmente devido à maior precipitação pluviométrica ocorrida no primeiro ano experimental (2001/02) de 1870mm (normal: $1586 \mathrm{~mm}$ ), levando com a água maiores quantidades de íons cálcio e magnésio do solo. A dureza da água no início do experimento encontravase mais alta (atingindo $63,2 \mathrm{mg} \mathrm{L}^{-1} \mathrm{CaCO}_{3}$ ) em janeiro, provavelmente devido à aplicação da calagem com cal virgem para desinfecção e calcário dolomítico para adubação, realizada na parcela experimental antes da entrada dos alevinos. ZWEIG et al. (1999) comenta que os níveis de dureza em tanques de piscicultura devem estar acima de $20 \mathrm{mg} \mathrm{L}^{-1} \mathrm{CaCO}_{3}$ a fim de obterse um bom desenvolvimento das espécies de peixes.
Na região sul do Brasil, esta varia de 32 a $180 \mathrm{mg} \mathrm{L}^{-1}$ $\mathrm{CaCO}_{3}$ (MARTINS, 1994).

Em experimentos com rizipiscicultura realizados em Bangladesh por HAROON \& PITTMAN (1997) com Puntius gonionotus e Oreochromis spp., os níveis de dureza total variaram de 80 a $160 \mathrm{mg} \mathrm{L}^{-1}$ $\mathrm{CaCO}_{3}$ e alcalinidade total de 60 a $100 \mathrm{mg} \mathrm{L}^{-1} \mathrm{CaCO}_{3}$, sendo considerados faixas adequadas para estas espécies. Já MOHANTY et al. (2004) encontraram variações de alcalinidade total entre 49 e $119 \mathrm{mg} \mathrm{L}^{-1}$ $\mathrm{CaCO}_{3}$ em rizipiscicultura. Os níveis de alcalinidade total têm mostrado diferenças entre as épocas de colocação dos alevinos, apresentando, assim como para a dureza total, variações devido a precipitações pluviométricas. Os níveis de dureza e alcalinidade total mantiveram-se mais baixos na parcela testemunha, possivelmente devido à inexistência de peixes para fazer a remoção do solo.

No presente experimento, os níveis de nitrito e amônia mantiveram-se baixos em todos os tratamentos, não sendo considerados tóxicos nestes valores. Estes dados estão de acordo com MOHANTY et al. (2004) que também obtiveram valores baixos para estes parâmetros, sendo para nitrito valores entre 0,0006 e $0,07 \mathrm{mg} \mathrm{L}^{-1}$ e para amônia total de 0,01 a $0,31 \mathrm{mg} \mathrm{L}^{-1}$.

\section{CONCLUSÕES}

As características físico-químicas da água (temperatura, $\mathrm{pH}$, dureza, alcalinidade,amônia e nitrito) não afetam o crescimento e o desenvolvimento dos peixes no consórcio com arroz irrigado para as espécies 
cultivadas (60\% de carpa húngara, 20\% de carpa capim, $10 \%$ de jundiá, $5 \%$ de carpa prateada e $5 \%$ de carpa cabeça grande). Embora as densidades de peixes utilizadas e as épocas de colocação dos alevinos afetem certos parâmetros de qualidade da água (oxigênio dissolvido e transparência da água) em alguns períodos, em geral, eles se mantém em níveis adequados de acordo com os padrões para as espécies.

\section{AGRADECIMENTOS}

Os autores agradecem ao Dr. Bernardo Baldisserotto, do Departamento de Fisiologia, e a doutoranda pela UFSCar, Lenise V. F. da Silva, pelas sugestões e assistência durante a realização dos experimentos, bem como a Fundação de Amparo à Pesquisa do Estado do Rio Grande do Sul (FAPERGS) pelo suporte financeiro. Golombieski e Marchezan, bolsistas do Conselho Nacional de Desenvolvimento Científico e Tecnológico (CNPq). Camargo, bolsista do Programa Institucional de Bolsas de Iniciação Científica (PIBIC). Santos, bolsista do Fundo de Incentivo a Pesquisa (FIPE).

\section{REFERÊNCIAS}

BALDISSEROTTO, B. Fisiologia de peixes aplicada à piscicultura. Santa Maria: UFSM, 2002. 212p.

BOYD, C.E.; EGNA, H.I. Dynamics of pond aquaculture. Boca Raton, New York: CRC Press, 1997.

CAStagnolli, N. Criação de peixes de água doce. Jaboticabal: FUNEP, 1992. 189p.

COSTA, O.T.F. et al. Susceptibility of the Amazonian fish, Colossoma macropomum (Serrasalminae), to shortterm exposure to nitrite. Aquaculture, v.232, p.627636, 2004.

COTRIM, D. et al. Agricultura Sustentável: rizipiscicultura. Manual prático. Porto Alegre: EMATER/ RS, 2001. 27p.

EL-SHAFAI, S.A. et al. Chronic ammonia toxicity to duckweed-fed tilapia (Oreochromis niloticus). Aquaculture, v.232, p.117-127, 2004.

EMBRAPA CLIMA TEMPERAdO (Pelotas). Arroz Irrigado: Recomendações técnicas da pesquisa para o Sul do Brasil. Embrapa Clima Temperado/IRGA/EPAGRI, 1999. 127p.

ESTEVES, F. de A. Fundamentos de Limnologia. Rio de Janeiro: Interciência, FINEP, 1988.

FLIK, G.; VERBOST, P.M. Celular mechanisms in calcium transport and homeostasis in fishes. Biochemistry and Molecular Biology of Fisches, v.5, p.252-263, 1995.

FRANCES, J. et al. The effects of nitrite on the short-term growth of silver perch (Bidyanus bidyanus). Aquaculture, v.163, p.63-72, 1998.

FOSS, A. et al. Growth and oxigen consumption in normal and $\mathrm{O}_{2}$ supersaturated water, and interactive effects of $\mathrm{O}_{2}$ saturation and ammonia on growth in spotted wolffish (Anarhichas minor Olafsen). Aquaculture v.224, p.105116, 2003.

GOLOMBIESKI, J.I. et al. Transport of silver catfish (Rhamdia quelen) fingerlings at different times, load densities and temperatures. Aquaculture, v.216, p.95-102, 2003.

GOMES, L.C. et al. Biologia do jundiá Rhamdia quelen (Teleostei, Pimelodidae). Ciência Rural, v.30, n.1, p.179185, 2000.

GREENBERG, A.E. et al. Standard Methods for the Examination of Water and Wastewater. 14.ed. Bru-El Graphic, Springfield. Illinois, 1976.

HAROON, A.K.Y.; PITTMAN, K.A. Rice-fish culure: feeding, growth and yield of two size classes of Puntius gonionotus Bleeker and Oreochromis spp. in Bangladesh. Aquaculture, v.154, p.261-281, 1997.

LOPES, J.M. et al. Survival and growth of silver catfish larvae exposed to different water pH. Aquaculture International, v.9, p.73-80, 2001.

MARTINS, E.L. A degradação ambiental de um trecho do Rio Vacacaí-Mirim. 1994. 116f. Monografia. Departamento de Geociências, CCNE, Universidade Federal de Santa Maria.

MOHANTY, R.K. et al. Performace evoluation of rice integration system in rainfed medium land ecosystem. Aquaculture, v.230, p.125-135, 2004.

PIPER, R.G. et al. Fish hatchery management United States Departament of the Interior. Washington, DC, 1982. 517p.

ROTHUIS, A.J. et al. Polyculture of silver barb, Puntius gonionotus (Bleeker), Nile tilapia, Oreochromis niloticus (L.), and common carp, Cyprinus carpio L., in Vietnamese ricefields: fish production parameters. Aquaculture Research, v.29, p.661-668, 1998.

SATO, G. Rizipiscicultura: uma alternativa rentável para o produtor de arroz irrigado. Agropecuária Catarinense, v.15, n.3, p.47-50, 2002.

SUMAGAYSAY-CHAVOSO, N.S.; SAN DIEGO-McGLONE, M.L. Water quality and holding capacity of intensive and semi-intensive milkfish (Chanos chanos) ponds. Aquaculture, v.219, p.413-429, 2003.

ZWEIG, R.D. et al. Source water quality for aquaculture. Washington: Word Bank, 1999. 62p.

WURTS, W.A.; DURBOROW, R.M. Interactions pf pH, carbon dioxide, alkalinity and hardness in fish ponds. Aquaculture Program, n.464, 4p, 1992. (SRACpublication). 